\title{
Yoğun Bakım Ünitelerindeki Enfeksiyonların Değerlendirilmesi: Çok Merkezli Nokta Prevalans Çalışması
}

\section{Evaluation of Infections in Intensive Care Units: A Multicentre Point-Prevalence Study}

\author{
Eşref ARAÇ ${ }^{1}$, Şafak KAYA ${ }^{2}$, Emine PARLAK ${ }^{3}$, Seyit Ali BÜYÜKTUNA ${ }^{4}$, Ali İrfan BARAN ${ }^{5}$, \\ Fethiye AKGÜL ${ }^{6}$, Mehmet Enes GÖKLER ${ }^{7}$, Selçuk AKSÖZ ${ }^{8}$, Ayşe SAĞMAK TARTAR ${ }^{9}$, \\ Recep TEKIN ${ }^{10}$, Yeşim YILDIZ ${ }^{11}$, Emrah GÜNAY ${ }^{1}$ \\ 1 SBÜ Gazi Yaşargil Eğitim ve Araştırma Hastanesi, iç Hastalıkları Kliniği, Diyarbakır. \\ 1 SBÜ Gazi Yaşargil Training and Research Hospital, Internal Medicine Clinic, Diyarbakır, Turkey. \\ 2 SBÜ Gazi Yaşargil Eğitim ve Araştırma Hastanesi, Enfeksiyon Hastalıkları ve Klinik Mikrobiyoloji Kliniği, Diyarbakır. \\ 2 SBÜ Gazi Yaşargil Training and Research Hospital, Infectious Diseases and Clinical Microbiology Clinic, \\ Diyarbakır, Turkey. \\ ${ }^{3}$ Atatürk Üniversitesi Tıp Fakültesi, Enfeksiyon Hastalıkları ve Klinik Mikrobiyoloji Anabilim Dalı, Erzurum. \\ ${ }^{3}$ Atatürk University Faculty of Medicine, Department of Infectious Diseases and Clinical Microbiology, Erzurum, Turkey. \\ ${ }^{4}$ Cumhuriyet Üniversitesi Tıp Fakültesi, Enfeksiyon Hastalıkları ve Klinik Mikrobiyoloji Anabilim Dalı, Sivas. \\ ${ }^{4}$ Cumhuriyet University Faculty of Medicine, Department of Infectious Diseases and Clinical Microbiology, Sivas, Turkey. \\ ${ }^{5}$ Yüzüncü Yıl Üniversitesi Tıp Fakültesi, Enfeksiyon Hastalıkları ve Klinik Mikrobiyoloji Anabilim Dalı, Van. \\ ${ }^{5}$ Yüzüncü Yıl University Faculty of Medicine, Department of Infectious Diseases and Clinical Microbiology, Van, Turkey. \\ ${ }^{6}$ Batman Devlet Hastanesi, Enfeksiyon Hastalıkları ve Klinik Mikrobiyoloji Kliniği, Batman. \\ ${ }^{6}$ Batman State Hospital, Infectious Diseases and Clinical Microbiology Clinic, Batman, Turkey. \\ ${ }^{7}$ Yıldırım Beyazıt Üniversitesi Tıp Fakültesi, Halk Sağlığı Anabilim Dalı, Ankara. \\ 7 Yıldırım Beyazıt University Faculty of Medicine, Department of Public Health, Ankara, Turkey. \\ ${ }^{8}$ Adıyaman Eğitim ve Araştırma Hastanesi, Enfeksiyon Hastalıkları ve Klinik Mikrobiyoloji Kliniği, Adıyaman. \\ ${ }^{8}$ Adıyaman Training and Research Hospital, Infectious Diseases and Clinical Microbiology Clinic, Adıyaman, Turkey. \\ ${ }^{9}$ Fırat Üniversitesi Tıp Fakültesi, Enfeksiyon Hastalıkları ve Klinik Mikrobiyoloji Anabilim Dalı, Elazığ. \\ ${ }^{9}$ Firat University Faculty of Medicine, Department of Infectious Diseases and Clinical Microbiology, Elazığ, Turkey. \\ ${ }^{10}$ Dicle Üniversitesi Tıp Fakültesi, Enfeksiyon Hastalıkları ve Klinik Mikrobiyoloji Anabilim Dalı, Diyarbakır. \\ 10 Dicle University Faculty of Medicine, Department of Infectious Diseases and Clinical Microbiology, Diyarbakır, Turkey. \\ ${ }^{11}$ Mardin Devlet Hastanesi, Enfeksiyon Hastalıkları ve Klinik Mikrobiyoloji Kliniği, Mardin. \\ ${ }^{11}$ Mardin State Hospital, Infectious Diseases and Clinical Microbiology Clinic, Mardin, Turkey.
}

Makale Atıfı: Araç E, Kaya Ş, Parlak E, Büyüktuna SA, Baran Ai, Akgül F, Gökler ME, Aksöz S, Sağmak Tartar A, Tekin R, Yıldız Y, Günay E. Yoğun bakım ünitelerindeki enfeksiyonların değerlendirilmesi: çok merkezli nokta prevalans çalışması. Mikrobiyol Bul 2019;53(4):364-373.

\section{Öz}

Enfeksiyon kontrolü özellikle başta yoğun bakım üniteleri (YBÜ) olmak üzere hastaneler için öncelikli bir hedeftir. YBÜ'de dünya çapında yaygınlık oranı \%30 olarak tahmin edilen enfeksiyonlar önemli bir morbidite ve mortalite nedenidir. Yoğun bakımda yatan hastalarda enfeksiyon riskini artıran pek çok 
faktör bilinmektedir. Bunların her birinde farklı enfeksiyonlar gelişebileceği için predispozan faktörlerin bilinmesi ve tanınması, tanı ve tedavinin erkenden yönlendirilmesine yardımcı olur. Bu çalışmada, bölgemizde yer alan sekiz ilimizdeki üniversite, eğitim araştırma ve devlet hastanelerinde yer alan erişkin YBÜ hastalarında yatan hastalardaki enfeksiyonlar, bu enfeksiyonlar arasında sağlık bakımı ile ilişkili infeksiyonların (SBIE) yaygınlığı, epidemiyolojisi, etkenler ve kullanılan antibiyotikler ile ilgili veriler, bu veriler ışığında SBiE önleme protokollerinin gözden geçirilmesi, nokta prevalans uygulanarak vurgulanması amaçlanmıştır. Bu çalışma, Türkiye'nin Doğu ve Güneydoğu Anadolu Bölgesi'nde yer alan sekiz ayrı ildeki (Sivas, Erzurum, Mardin, Batman, Diyarbakır, Elazığ, Van, Adıyaman) toplam dokuz hastanede yer alan erişkin YBÜ'de takip edilen hastalarda gerçekleştirilmiştir. Bu hastaneler yatak sayıları 358-1418 arasında değişen, altısı üniversite, biri eğitim araştırma, ikisi devlet hastanesi olarak belirlenmiştir. Ortak bir gün belirlenip aynı gün çalışmaya katılan hastanelerdeki araştırmacılar tarafından tüm erişkin YBÜ hastalarına prospektif olarak sürveyans uygulanmıştır. Hastaların demografik bilgileri, altta yatan hastalıkları, hospitalizasyon süresi, invaziv girişim varlığı (üriner kateter, santral venöz kateter, eksternal ventriküler drenaj, mekanik ventilatör), yanık, travma, cerrahi gibi risk faktörlerinin olup olmadığı, enfeksiyonu olan olgu sayısı, enfeksiyon bölgesi, enfeksiyon tipi (hastane kökenli, toplum kökenli), üreyen mikroorganizma türü, polimikrobiyal mi monomikrobiyal mi olduğu, alınan antibiyotikler, antibiyotik kullanım süresi gibi veriler toplanarak veriler tüm araştırmacılar tarafından kaydedilmiştir. Çalışmamızda sekiz ayrı ildeki toplam dokuz hastanenin erişkin YBÜ'sünde yatan 429 hastanın verisi incelenmiştir. Toplamda 881 yoğun bakım yatağı bulunan bu hastanelerde yatak doluluk oranı \%84 (740 yatak) olarak tespit edilmiştir. Çalışma grubunun \%49.7'si erkek olarak belirlenirken, yaş ortalaması (min-max) $64.08 \pm 18.78$ (2-97) yıl olarak belirlenmiştir. SBiE nokta prevalansı \%21.7 ( $\mathrm{n}=93$ ) olarak saptanmıştır. Takip edilen hastalarda tespit edilen enfeksiyon sayısı 182 (\%42.4) olarak belirlenmiştir. Bu enfeksiyonların \%21.4'ü toplum kökenli pnömoni, \%18.6'sı ventilatör ilişkili pnömoni (ViP), \%16.3'ü toplum kökenli üriner sistem enfeksiyonu, \%16.3'ü kan dolaşımına bağlı enfeksiyondur. Ayrıca, çalışma grubunda en çok kullanılan antibiyotikler sırasıyla, piperasilin/tazobaktam, karbapenem, kinolon ve seftriakson olarak bulunmuştur. En sık görülen SBiE türü sırasıyla ventilasyonla ilişkili pnömoni (\%8.9) ve kan dolaşımı enfeksiyonu (\%8.2)'dur. Bireylerin hastanede ortalama $32.05 \pm 66.85$ (1-459) gün yattığı ve SBiE tespit edilenlerin ortalama $7.76 \pm 7.11$ (141) gün antibiyotik kullandıkları tespit edilmiştir. Enfeksiyon ile mücadele etmede bugün en yaygın olarak kabul edilen yöntem aktif, prospektif ve hasta bazlı sürveyans çalışmalarının düzenli olarak yürütülmesi ve elde edilen verilere göre kontrol önlemlerinin alınması ve uygun tedavinin düzenlenmesidir. Bölgemizde SBiE oranının yüksek olmasını personel eksikliği, malzeme eksikliği, uygunsuz antibiyotik kullanımı, fiziki koşulların yetersizliği, enfeksiyon kontrol komitelerine yeterli desteğin verilmemesi olarak düşünülmüştür. Bu nedenle, SBiE önlenmesi için gerekli önlemlerin alınmasında hastane yönetimi ile işbirliği içerisinde olmanın ve gerekli desteğin sağlanması önemlidir.

Anahtar kelimeler: Yoğun bakım ünitesi; enfeksiyon; nokta prevalans.

\section{ABSTRACT}

Infection control is a top priority for hospitals, especially in intensive care units (ICU). In intensive care units, prevalence of infection is estimated to be $30 \%$ worldwide, which is a major cause of morbidity and mortality. Many factors are known to increase the risk of infection in ICU patients. Since each of these may lead to different infections, it is important to recognize and identify predisposing factors for early diagnosis and treatment. The regional health care-associated infections (HCAl) prevalence and distribution of risk factors are important strategies in infection control. In this regard, the aim of this point prevalence study was to obtain data related to infections, the prevalence of HCAl among these infections, the epidemiology, agents and antibiotics used among adult ICU patients in the university hospitals, training and research hospitals and public hospitals located in eight of the cities of our region. In the light of these data, we aimed to review and emphasize the guidelines on HCAl prevention. The study included adult ICU patients followed up in nine hospitals in the Eastern and South-eastern Anatolia Regions of eight different cities (Sivas, Erzurum, Mardin, Batman, Diyarbakir Elazig, Van, Adiyaman) in Turkey. Of the hospitals six were university hospitals, one was training and research hospital, and two were public hospitals. The number of beds ranged from 358 to 1418 . A specific day was determined on which the 
Yoğun Bakım Ünitelerindeki Enfeksiyonların Değerlendirilmesi: Çok Merkezli Nokta Prevalans Çalışması

researchers concurrently carried out a prospective surveillance in all adult intensive care unit patients. The researchers collected data and recorded the demographic characteristics (age, gender), underlying diseases, length of hospital stay, presence of invasive intervention (urinary catheter, central venous catheter, external ventricular drainage, mechanical ventilator, presence of risk factors such as burn, trauma and surgery, number of infection cases, type of infection (hospital-acquired, community-acquired), type of microorganisms and whether polymicrobial or monomicrobial, which antibiotics were administered, and duration of antibiotic treatment. Our study assessed data of 429 inpatients in the adult ICU of nine hospitals in eight different cities. There were a total of 881 intensive care beds in these hospitals, and 740 (84\%) beds were occupied. Of the study group $49.7 \%$ was male with a mean age (min-max) of $64.08 \pm 18.78(2-97)$ years. The point prevalence of HCAl was $21.7 \%(n=93)$. Of the patients who were followed-up $182(42.4 \%)$ presented infections. Of these infections, $21.4 \%$ were diagnosed as community-acquired pneumonia, $18.6 \%$ were ventilator-associated pneumonia (VAP), $16.3 \%$ were communityacquired urinary tract infection (UTI), and $16.3 \%$ were bloodstream infection. In addition, the most commonly administered antibiotics in the study group were piperacillin/tazobactam, carbapenem, quinolone and ceftriaxone, respectively. The most common types of HCAl were community-acquired pneumonia $(10.7 \%)$, ventilator-associated pneumonia $(8.9 \%)$ and bloodstream infections $(8.2 \%)$. The mean length of hospital stay was $32.05 \pm 66.85$ (1-459) days and the mean duration of antibiotic therapy in patients with HCAls was $7.76 \pm 7.11$ (1-41) days. The most widely accepted method to handle infection is to carry out active, prospective and patient-based surveillance studies on a regular basis, and to take control measures and arrange appropriate treatment in the light of the data obtained. We attribute the high prevalence of HCAl in our region to lack of personnel, lack of materials, inappropriate use of antibiotics, insufficiency of physical conditions, and little support for infection control committees. In conclusion, we emphasize that it is of importance to work closely with the hospital administration to take measures and that necessary assistance is provided.

Keywords: Intensive care unit; infections; point-prevalence.

\section{Giriş̧}

Enfeksiyon kontrolü özellikle başta yoğun bakım üniteleri (YBÜ) olmak üzere hastaneler için öncelikli bir hedeftir. YBÜ'lerde dünya çapında yaygınlık oranı \%30 olarak tahmin edilen enfeksiyonlar önemli bir morbidite ve mortalite nedenidir ${ }^{1-4}$. Erişkin hastalar arasında YBÜ kaynaklı enfeksiyon insidansı gelişmiş ülkelerde \%17 iken, düşük ve orta gelirli ülkelerde \%4.4 ile \%88.9 arasında değişmektedir. Ülkemiz gibi düşük-orta gelir düzeyindeki ülkelerde, YBÜ kaynaklı enfeksiyon sıklığı, yüksek gelirli ülkelerdekinden 2-3 kat daha fazladır 5 .

YBÜ'lerdeki önemli sorunlardan olan sağlık bakımı ile ilişkili enfeksiyonlar (SBiE), hastane kaynaklı enfeksiyonlar olarak tanımlandığı 19. yüzyıl ortalarından bugüne kadar önemini sürdürmektedir ${ }^{6}$. SBiE kontrolü ve önlenmesi için etkili programların geliştirilmesi hem hasta güvenliği hem de kalite standartları açısından önemlidir. Aksi ispat edilmediği sürece her hastane enfeksiyonu, temel enfeksiyon kontrol kurallarına uyulduğu takdirde önlenmesi mümkün olan bir tıbbi hata olarak kabul edilmelidir ${ }^{7}$.

YBÜ'de yatan hastalarda enfeksiyon riskini artıran pek çok faktör bilinmektedir. Bunların her birinde farklı enfeksiyonlar gelişebileceği için predispozan faktörlerin bilinmesi ve tanınması, tanı ve tedavinin erkenden yönlendirilmesine yardımcı olmaktadır. Bu faktörler; iyatrojenik nedenler (el hijyeninin sağlanmaması, invaziv girişimlerin uygulanması, geniş spektrumlu antibiyotik kullanılması vb.), anatomik bariyerlerde defektlerin varlı̆̆ 
(yanık, cerrahi girişim gibi) olarak sayılabilir. Bunların varlığında tanıya yönelik girişimlerin yanı sıra profilaktik veya ampirik antibiyotiklerin kullanımı göz önünde bulundurulmalıdır?.

Etkin bir enfeksiyon kontrol programı, hastanede yatış süresini kısaltıp morbidite ve mortaliteyi azaltarak hasta memnuniyetini artırmanın yanında, ilaç ve diğer sarf malzemelerin uygun kullanımını en üst düzeye çıkararak maliyeti düşürmektedir. Ülkemize benzer şekilde gelişmekte olan ülkelerdeki SBIE'nin artan yükünün daha doğru şekilde değerlendirilmesi gerekmektedir. Enfeksiyon kontrolündeki önemli problemler arasında personel ve malzeme eksikliği, mikrobiyoloji laboratuvarlarına erişim eksikliği ve enfeksiyon kontrol komitelerine yeterli idari desteğin sağlanmaması sayılabilir ${ }^{8-10}$.

Bölgesel olarak SBIE hızımızı, etken dağılımını bilmek enfeksiyon kontrolünün önemli stratejilerindendir. Bu çalışmada, bölgemizde yer alan sekiz ilimizdeki üniversite, eğitim araştırma ve devlet hastanelerinde yer alan erişkin YBÜ hastalarında yatan hastalardaki enfeksiyonlar, bu enfeksiyonlar arasında SBIE yaygınlığı, epidemiyolojisi, etkenler ve kullanılan antibiyotikler ile ilgili veriler, bu veriler ışığında SBiE önleme protokollerinin gözden geçirilmesi nokta prevalans uygulanarak vurgulanması amaçlanmıştır.

\section{GEREÇ ve YÖNTEM}

Bu çalışma, Sağlık Bilimleri Üniversitesi Gazi Yaşargil Eğitim ve Araştırma Hastanesi Klinik Araştırmalar Etik Kurulu onayı ile gerçekleştirildi (Tarih: 27.04.2018 ve Karar no: 76).

Bu çalışma, Türkiye'nin Doğu ve Güneydoğu Anadolu Bölgesinde yer alan sekiz ayrı ildeki (Sivas, Erzurum, Mardin, Batman, Diyarbakır, Elazığ, Van, Adıyaman) toplam dokuz hastanede (Diyarbakır ilinde iki hastane) yer alan erişkin YBÜ'de takip edilen hastalarda gerçekleştirildi. Bu hastanelerin altısı üniversite, biri eğitim araştırma, ikisi ise devlet hastanesiydi. Yatak sayıları 358-1418 arasında değişmekteydi. Hastaneler eğitim araştırma hastaneleri, üniversite hastaneleri ve devlet hastaneleri olarak sınıflandırıldı. Ortak bir gün belirlenip aynı gün çalışmaya katılan hastanelerdeki araştırmacılar tarafından tüm erişkin YBÜ hastalarına prospektif sürveyans yapıldı. Tüm veriler hasta dosya ve gözlemlerinden elde edildi. Gerektiğinde doğrudan hasta muayenesinden de yararlanıldı. Hastaların demografik bilgileri (yaş, cinsiyet), altta yatan hastalıkları, hastanede yatış süresi, invaziv girişim varlığı (üriner kateter, santral venöz kateter, eksternal ventriküler drenaj, mekanik ventilatör), yanık, travma, cerrahi gibi risk faktörlerinin olup olmadığı, enfeksiyon olgularının sayısı, enfeksiyon türü, enfeksiyon tipi (hastane kökenli, toplum kökenli), üreyen mikroorganizma türü, polimikrobiyal/monomikrobiyal oluşu, tedavide kullanılan antibiyotikler, antibiyotik kullanım süresi gibi veriler toplandı ve tüm araştırmacılar tarafından kaydedildi.

\section{İstatistiksel Analiz}

Risk faktörleri arasındaki ilişkiyi değerlendirmek ve yaş gibi nümerik veriler için Student t-testi, kategorik veriler için Fisher exact testi veya ki-kare testi kullanılarak karşılaştırıldı. 
Yoğun Bakım Ünitelerindeki Enfeksiyonların Değerlendirilmesi:

Çok Merkezli Nokta Prevalans Çalışması

P değeri 0.05 'ten küçük veya ona eşit olması anlamlı olarak kabul edildi. İstatistiksel analizler SPSS 16.0 programı kullanılarak yapıldı.

\section{BULGULAR}

Çalışmamızda sekiz ayrı ildeki toplam dokuz hastanenin erişkin YBÜ'de yatan 429 hastaya ait veri incelenmiştir. Bu hastanelerde bulunan toplam 881 yoğun bakım yatağının 740 (\%84)'ında doluluk tespit edilmiştir. Çalışma grubunun \%49.7'si erkek hastalardan oluşurken, yaş ortalaması (min-max) $64.08 \pm 18.78$ (aralık: 2-97) yıl bulunmuştur. Çalışmaya yalnız erişkin YBÜ'ler dahil edilmiştir. Ancak, travma nedeniyle ya da beyin cerrahi ve göğüs cerrahi klinikleri tarafından erişkin YBÜ'lerde takip edilen çocuk hastalar bulunmaktadır. SBIE nokta prevalansı \%21.7 $(n=93)$, toplum kökenli enfeksiyon oranı \%20.7 $(n=89)$ ve toplam enfeksiyon görülme oranı \%42.4 $(n=182)$ olarak tespit edilmiştir. Bu enfeksiyonların \%21.4'ü toplum kökenli pnömoni (TKP), \%18.6'sı ventilatörle ilişkili pnömoni (VIP), \%16.3'ü toplum kökenli üriner sistem enfeksiyonu (ÜSE) ve \%16.3'ü kan dolaşımı enfeksiyonu (KDE) tanısı alan hastalardan oluşuyordu. Çalışmanın yapıldığı hastanelerin özellikleri ile SBIE tespit edilen hastaların şehirlere göre dağılımı Tablo I'de verilmiştir.

Hastalar sıklıkla anestezi (\%29.4), dahiliye (\%17.3), kardiyoloji (\%16.3) ve nöroloji (\%12.1) YBÜ'lerinde yatmaktayken, tedavide en çok kullanılan antibiyotikler sırasıyla, piperasilin/tazobaktam (\%29.4), karbapenem (\%18.7), florokinolon (\%12.2) ve seftriakson (\%10.0) olarak belirlenmiştir. Çalışma grubunda kullanılan antibiyotiklerin ve hastaların yattığı YBÜ dağılımı Şekil 1 ve 2'de verilmiştir.

Enfeksiyon ile cinsiyet, travma ve cerrahi girişim varlığı arasında fark bulunamamıştır (her biri için; p> 0.05). Malignite, kronik obstrüktif akciğer hastalığı (KOAH), kronik böb-

Tablo I. Çalışmanın Yapıldığı Hastanelerin Özellikleri ile SBiE Tespit Edilen Hastaların Şehirlere Göre Dağılımı.

\begin{tabular}{|c|c|c|c|c|c|c|}
\hline ì & $\begin{array}{l}\text { İldeki toplam } \\
\text { hastane sayısı } \\
\text { (IIIden alınan } \\
\text { hastane sayısı) }\end{array}$ & $\begin{array}{l}\text { Çalışmaya alınan } \\
\text { hastanenin } \\
\text { toplam yatak } \\
\text { kapasitesi }\end{array}$ & $\begin{array}{l}\text { Hastanelerin } \\
\text { yoğun } \\
\text { bakım yatak } \\
\text { kapasitesi }\end{array}$ & $\begin{array}{c}\text { Yoğun bakım } \\
\text { yatağı işgal } \\
\text { oranı }\end{array}$ & $\begin{array}{c}\text { Toplum kökenli } \\
\text { enfeksiyon } \\
\text { tespit edilen } \\
\text { hasta sayısı } \\
\text { n (\%) }\end{array}$ & $\begin{array}{l}\text { SBIE tespit } \\
\text { edilen } \\
\text { hasta } \\
\text { sayısı } \\
\text { n (\%) }\end{array}$ \\
\hline Adıyaman & $1(1)$ & 521 & 70 & 92 & $7(15.6)$ & $7(15.6)$ \\
\hline Erzurum & $5(1)$ & 1418 & 142 & 49 & $11(15.9)$ & $9(13.0)$ \\
\hline Batman & $2(1)$ & 357 & 56 & 50 & $9(18.0)$ & $14(28.0)$ \\
\hline Sivas & $2(1)$ & 1150 & 73 & 84 & $15(24.6)$ & $12(19.7)$ \\
\hline Diyarbakır & $5(2)$ & 650 & 95 & 91 & $2(1.9)$ & $18(17.8)$ \\
\hline Mardin & $1(1)$ & 386 & 23 & 78 & $9(50.0)$ & $5(27.8)$ \\
\hline Van & $2(1)$ & 680 & 87 & 91 & $27(54.0)$ & $11(22.0)$ \\
\hline Elazığ & $4(1)$ & 1100 & 75 & 85 & $9(31.0)$ & $17(58.6)$ \\
\hline Toplam & $22(9)$ & 7571 & 881 & 77.5 & $89(20.7)$ & $93(21.7)$ \\
\hline
\end{tabular}

SBiE: Sağlık bakımı ile ilişkili enfeksiyon. 


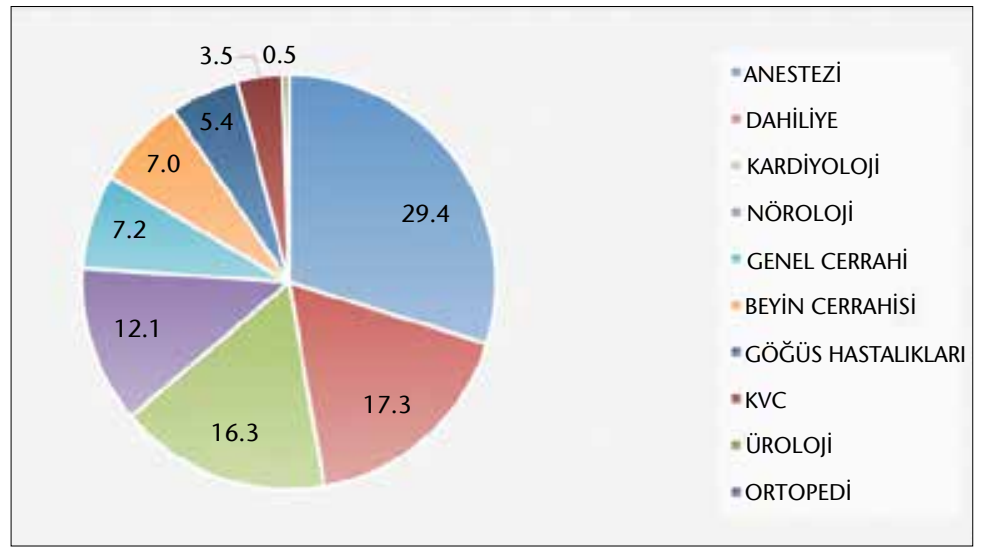

Şekil 1. Çalışma grubunun yattığı yoğun bakım ünitesi dağıımı.

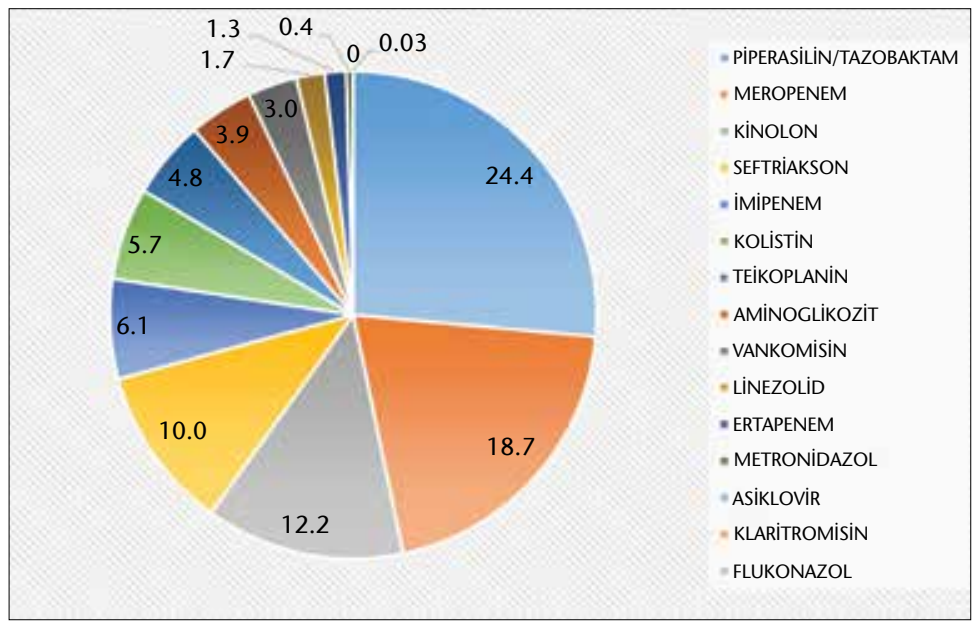

Şekil 2. Çalışma grubunda kullanılan antibiyotiklerin dağılımı.

rek yetmezliği (KBY) gibi ek hastalığı olanlarda, santral ve üriner kateteri olanlarla mekanik ventilasyona bağlı olanlarda ve üçüncü basamak YBÜ'de yatanlarda SBiE daha sık bulunmuştur (Tablo II). Hastane enfeksiyonu varlığının bazı risk faktörlerine göre dağılımı Tablo II'de verilmiştir.

Çalışmamızda en sık görülen SBIE tipi sırasıyla VIP (\%8.9) ve KDE (\%8.2) olarak belirlenmiştir. Bireylerin hastanede ortalama $32.05 \pm 66.85$ (1-459) gün yattığı ve SBiE tespit edilenlerin ortalama $7.76 \pm 7.11$ (1-41) gün antibiyotik kullandıkları tespit edilmiştir. Hastanede yatış süresi, TKP, VIP, nozokomiyal ÜSE ve KDE olanlarda olmayanlara göre daha fazla bulunmuştur (Tablo III). TKP, ViP, KDE ve menenjit tanısı alan hastaların daha uzun süre antibiyotik kullandığı anlaşılmıştır (Tablo III). Enfeksiyon türlerine göre hastaların yatış ve antibiyotik kullanma sürelerinin dağılımı Tablo III'te verilmiştir. 


\begin{tabular}{|c|c|c|c|}
\hline & & $\begin{array}{c}\text { SBiE varlığı } \\
\text { n (\%) }\end{array}$ & $\begin{array}{l}\text { Test } \\
\mathrm{X}^{2} ; \mathrm{p} \\
\end{array}$ \\
\hline \multirow[t]{2}{*}{ Cinsiyet } & Kadın & $96(44.4)$ & $0.721 ; 0.394$ \\
\hline & Erkek & $86(40.4)$ & \\
\hline \multicolumn{4}{|l|}{ Komorbidite } \\
\hline Diabetes mellitus & Var & $40(48.8)$ & $1.677 ; 0.195$ \\
\hline Malignite & Var & $25(67.6)$ & $10.480 ; 0.001$ \\
\hline Kronik obstrüktif akciğer hastalığı & Var & $31(59.6)$ & $7.159 ; 0.007$ \\
\hline Kronik böbrek yetmezliği & Var & $22(57.9)$ & $4.085 ; 0.043$ \\
\hline Konjestif kalp hastalığı & Var & $33(43.4)$ & $0.038 ; 0.846$ \\
\hline Serebrovasküler hastalık & Var & $44(50.6)$ & $2.968 ; 0.085$ \\
\hline Santral kateter & Var & $102(58.0)$ & $29.468 ;<0.001$ \\
\hline Üriner kateter & Var & $179(49.3)$ & $41.167 ;<0.001$ \\
\hline Mekanik ventilasyon & Var & $97(59.1)$ & $30.394 ;<0.001$ \\
\hline Travma & Var & $17(44.7)$ & $0.091 ; 0.763$ \\
\hline Cerrahi girişim & Var & $38(45.8)$ & $0.475 ; 0.491$ \\
\hline \multirow[t]{3}{*}{ Yoğun bakım ünitesi } & 1. basamak & $3(16.7)$ & $30.889 ;<0.001$ \\
\hline & 2. basamak & $21(16.4)$ & \\
\hline & 3. basamak & $158(50.5)$ & \\
\hline
\end{tabular}

\section{TARTIŞMA}

SBIE'ler, çağımızın başta gelen sağlık sorunlarından biridir. Hastaneye ve hastane bölümlerine göre değişmekle birlikte hastaneye yatan her 100 hastadan üç ile onunda sağlık sorunlarına çözüm beklerken SBiE gelişmektedir. Bunun sonucunda hastanede kalış süresi uzamakta, tedavi maliyeti artmakta ve bazı hastalar yaşamını kaybetmektedir. SBiE'ler, bu yönleri ile ön plana çıkarken bir diğer önemli özellikleri de kısmen önlenebilir olmalarıdır. Etkin enfeksiyon kontrol önlemlerinin uygulanması ile riskler ve bu enfeksiyonların görülme sıklığı azaltılabilmektedir. Ancak sağlık sistem teknolojilerinin gelişimi ve bakım hizmetlerindeki kalite standartlarının artmasıyla pek çok hastanın yaşam süresi uzamıştır. Bunun sonucu olarak altta yatan hastalık sayısı artmış ve bu hastalıkların tanı ve tedavisine yönelik yapılan invaziv girişimler, uygulanan tedaviler enfeksiyon gelişim riskini arttırmış$\operatorname{tır}^{11}$. Yatan hastalarda enfeksiyon görülme sıklığı yüksek olup, pnömoniler, KDE ve ÜSE en sık görülen enfeksiyonlardır ${ }^{12}$. Bu enfeksiyonlar komorbid hastaların takip edildiği, invaziv girişimlerin yüksek oranda kullanıldığı YBÜ'lerde en fazladır ${ }^{12}$. Bizim çalışmamızın sonuçları literatür bilgileri ile korele şekilde düşük ve orta gelirli ülkelerdeki sonuçlara benzerdir $^{13,14}$. En sık görülen SBIE türü sırasıyla ViP (\%8.9) ve KDE (\%8.2)'dir. 
Tablo III. Enfeksiyon Türlerine Göre Hastaların Yatış ve Antibiyotik Kullanma Sürelerinin Dağılımı

\begin{tabular}{|c|c|c|c|c|c|c|}
\hline & & \multirow[b]{2}{*}{ n (\%) } & \multicolumn{2}{|c|}{ Hastanede yatış süresi } & \multicolumn{2}{|c|}{ Antibiyotik kullanma süresi* } \\
\hline & & & $\begin{array}{c}\text { Ortalama } \pm \text { SD } \\
(\min -\max )\end{array}$ & $Z ; p$ & $\begin{array}{c}\text { Ortalama } \pm \\
\text { SD (min-max) }\end{array}$ & $Z ; p$ \\
\hline \multirow{4}{*}{$\begin{array}{l}\text { Toplum kökenli } \\
\text { pnömoni }\end{array}$} & Yok & $386(89.3)$ & $35.0 \pm 70.1$ & $3.128 ; 0.002$ & $8.54 \pm 7.37$ & $3.490 ;<0.001$ \\
\hline & & & $(1.0-459.0)$ & & $1.00-41.00$ & \\
\hline & Var & $46(10.7)$ & $7.9 \pm 11.6$ & & $5.42 \pm 5.71$ & \\
\hline & & & $(1.0-68.0)$ & & $1.00-27.00$ & \\
\hline \multirow{4}{*}{$\begin{array}{l}\text { Ventilatörle } \\
\text { ilişkili pnömoni }\end{array}$} & Yok & $391(91.1)$ & $29.4 \pm 67.0$ & $6.442 ;<0.001$ & $7.37 \pm 7.15$ & $2.641 ; 0.008$ \\
\hline & & & $(1.0-459.0)$ & & $1.00-41.00$ & \\
\hline & Var & $38(8.9)$ & $59.5 \pm 59.8$ & & $9.28 \pm 6.82$ & \\
\hline & & & $(4.0-293.0)$ & & $3.00-40.00$ & \\
\hline \multirow{4}{*}{$\begin{array}{l}\text { Toplum kökenli } \\
\text { üriner sistem } \\
\text { enfeksiyonu }\end{array}$} & Yok & $416(97.0)$ & $32.8 \pm 67.8$ & $0.818 ; 0.413$ & $7.79 \pm 7.13$ & $0.301 ; 0.764$ \\
\hline & & & $(1.0-459.0)$ & & $1.00-41.00$ & \\
\hline & Var & $13(3.0)$ & $9.2 \pm 8.7$ & & $7.46 \pm 7.05$ & \\
\hline & & & $(1.0-33.0)$ & & $1.00-27.00$ & \\
\hline \multirow{4}{*}{$\begin{array}{l}\text { Nozokomiyal } \\
\text { üriner sistem } \\
\text { enfeksiyonu }\end{array}$} & Yok & $397(92.5)$ & $30.0 \pm 66.3$ & $4.084 ;<0.001$ & $7.80 \pm 7.45$ & $0.565 ; 0.572$ \\
\hline & & & $(1.0-459.0)$ & & $1.00-41.00$ & \\
\hline & Var & $32(7.5)$ & $57.3 \pm 70.0$ & & $7.63 \pm 5.31$ & \\
\hline & & & $(2.0-283.0)$ & & $1.00-22.00$ & \\
\hline \multirow{4}{*}{$\begin{array}{l}\text { Kan dolaşımı } \\
\text { enfeksiyonu }\end{array}$} & Yok & $394(91.8)$ & $29.0 \pm 63.7$ & $4.777 ;<0.001$ & $7.20 \pm 7.12$ & $3.382 ; 0.001$ \\
\hline & & & $(1.0-459.0)$ & & $1.00-41.00$ & \\
\hline & Var & $35(8.2)$ & $66.4 \pm 89.4$ & & $10.15 \pm 6.66$ & \\
\hline & & & $(2.0-323.0)$ & & $1.00-36.00$ & \\
\hline \multirow[t]{4}{*}{ Menenjit } & Yok & $424(98.8)$ & $32.3 \pm 67.2$ & $15.77 ; 0.155$ & $7.88 \pm 7.14$ & $1.966 ; 0.049$ \\
\hline & & & $(1.0-459.0)$ & & $1.00-41.00$ & \\
\hline & Var & $5(1.2)$ & $6.8 \pm 9.8$ & & $2.75 \pm 2.36$ & \\
\hline & & & $(1.0-24.0)$ & & $1.00-6.00$ & \\
\hline \multirow{4}{*}{$\begin{array}{l}\text { Yumuşak doku } \\
\text { enfeksiyonu }\end{array}$} & Yok & $420(97.9)$ & $32.0 \pm 67.0$ & $0.814 ; 0.416$ & $7.94 \pm 7.23$ & $1.477 ; 0.140$ \\
\hline & & & $(1.0-459.0)$ & & $1.00-41.00$ & \\
\hline & Var & $9(2.1)$ & $34.4 \pm 64.0$ & & $4.44 \pm 2.65$ & \\
\hline & & & $(2.0-203.0)$ & & $2.00-9.00$ & \\
\hline \multirow{4}{*}{$\begin{array}{l}\text { Cerrahi alan } \\
\text { enfeksiyonu }\end{array}$} & Yok & $420(97.9)$ & $32.3 \pm 67.5$ & $1.082 ; 0.279$ & $7.53 \pm 6.70$ & $0.848 ; 0.396$ \\
\hline & & & $(1.0-459.0)$ & & $1.00-41.00$ & \\
\hline & Var & $9(2.1)$ & $21.3 \pm 16.9$ & & $12.33 \pm 12.39$ & \\
\hline & & & $(2.0-48.0)$ & & $1.00-36.00$ & \\
\hline \multirow{4}{*}{$\begin{array}{l}\text { Nozokomiyal } \\
\text { pnömoni }\end{array}$} & Yok & 412 (96.0) & $32.5 \pm 68.1$ & $1.814 ; 0.070$ & $7.79 \pm 7.18$ & $0.127 ; 0.899$ \\
\hline & & & $(1.0-459.0)$ & & $1.00-41.00$ & \\
\hline & Var & $17(4.0)$ & $19.9 \pm 16.3$ & & $7.59 \pm 6.62$ & \\
\hline & & & $(2.0-58.0)$ & & $1.00-25.00$ & \\
\hline
\end{tabular}


Yoğun Bakım Ünitelerindeki Enfeksiyonların Değerlendirilmesi: Çok Merkezli Nokta Prevalans Çalışması

Çalışmamızda SBiE nokta prevalansı \%21.7 ( $\mathrm{n}=93)$ olarak tespit edildi. Bu oran ABD'de 183 hastanede 11.282 hasta üzerinde yapılan çalışmada \%4 olarak bulunmuştur $^{13}$. İsveç'te 21.904 hasta üzerinde yapılan çalışmada \%7.8 ve İtalya'da yapılan başka bir çalışmada \%9.2 olarak tespit edilmiştir ${ }^{15,16}$. Ülkemizde İzmir, Ankara ve İstanbul'da yapılan çalışmalarda sırasıyla \%7.2, \%13.1, \%11.4 tespit edilmiştir ${ }^{11,14,17}$. Görüldüğü üzere, çalışmada saptanan oranlar hem yurt dışındaki çalışmalara göre hem de yurt içindeki gelişmiş illerde yapılan çalışmalara göre oldukça yüksektir. Bölgemizdeki oranın daha yüksek olma nedeninin sosyoekonomik düzey düşüklüğünden kaynaklandığı düşünülmüştür. Çalışmamızda en yüksek SBiE görülen il \%58.6 oranıyla Elazığ, en düşük il \%13 ile Erzurum olarak tespit edilmiştir

Çalışmada en çok kullanılan antibiyotikler sırasıyla, piperasilin/tazobaktam (\%29.4), karbapenem (\%18.7), florokinolon (\%12.2) ve seftriakson (\%10.0) olarak belirlenmiştir. 2018 yılında Hacettepe Üniversitesinde yapılan tez çalışmasında da benzer özellikler tespit edilmiştir ${ }^{18}$.

Malignite, KOAH olan hastalar ile üriner kateteri bulunan hastalarda enfeksiyon sıklığı diğer çalışmalara benzer şekilde yüksek bulunmuştur ${ }^{17}$. KBY olan hastalar ile mekanik ventilasyona bağlı olan hastalar tüm çalışmalarda olduğu gibi SBiE açısından risk faktörü olarak bulunmuştur ${ }^{14}$. SBIE tespit edilen hastaların toplum kökenli enfeksiyon tespit edilen hastalara göre beklendiği gibi hastanede daha uzun süre yattığı ve antibiyotik aldığı tespit edilmiştir.

SBIE'lerin önlenebilmesi için etkin bir sürveyans yapılması, enfeksiyon etkenleri ve direnç profillerinin sürekli ve etkin şekilde izlenmesi, bu izlem sonuçlarına göre kontrol önlemleri alınarak ileriye dönük etkin enfeksiyon kontrol stratejilerinin geliştirilmesi gerekmektedir.

Bölgemizde SBIE oranının yüksek olması; hastanelerimizde personel eksikliğinin olması, dönem dönem tıbbi malzeme eksikliği yaşanması, uygunsuz antibiyotik kullanım oranlarımızın yüksek olması, izolasyon için fiziki koşulların yetersizliği, enfeksiyon kontrol komitelerine idarelerimiz tarafından yeterli desteğin verilmemesi olarak düşünülmüştür. Ancak, bu eksikliklerin giderilebilmesiyle enfeksiyon kontrol önlemlerinin etkin şekilde sağlanabileceği kanısına varılmıştır.

\section{ÇIKAR ÇATIŞMASI}

Yazarlar bu makale ile ilgili herhangi bir çıkar çatışması bildirmemişlerdir.

\section{KAYNAKLAR}

1. Haque M, Sartelli M, McKimm J, Abu Bakar M. Health care-associated infections - an overview. Infect Drug Resist 2018;11:2321-33.

2. WHO Healthcare-associated infections. Fact Sheet. [Accessed April 1, 2019]. Availablefrom:http://www. who.int/gpsc/country_work/gpsc_ccisc_fact_sheet_en.pdf.

3. Yeşilbağ Z, Çağatay A, Karadeniz A, Başaran S, Orhun G, Özca P, et al. Yoğun bakım birimindeki hastaların rektal kolonizasyonu ile hastane enfeksiyonu arasında bir ilişki var mı? Mikrobiyol Bul 2015;49(3):327-39. 
4. Yenilmez E, Ülçay A, Görenek L, Diktaş H. The current definitions of health-care associated infections in intensive care units. J Clin Anal Med 2015;6(3):401-5.

5. Ağırbaş I, Akbulut Y, Azap A, Çiftçi E, Önder Ö, Doğanay Payzıner P, et. al. Cost analysis of health are associated infections. Ankara Üniversitesi Tıp Fakültesi Mecmuası 2015;68(2):71-6.

6. Yurdakul ES. Kızılay'ın ilk hastaneleri (1877-1878): Yatan hastalarda görülen infeksiyonlar ve mortalite oranları. Türk Mikrobiyoloji Cem Derg 2019;49(2):104-12.

7. Bulut A, Şengül H. Sağlık hukuku yönünden hastane enfeksiyonlarının değerlendirilmesi. Int J Social Human Scien Res 2018;5(17):275-83.

8. Khan H, Baig F, Mehboob R. Nosocomial infections: epidemiology, prevention, control and surveillance. Asian Pacific J Trop Biomed 2017;7(5):478-82.

9. Weinshel K, Dramowski A, Hajdu A, Jacob S, Khanal B, Zoltân M, et al. Gap analysis of infection control practices in low-and middle-income countries. Infect Control Hosp Epidemiol 2015;36:1208-14.

10. Iliyasu G, Daiyab FM, Tiamiyu AB, Abubakar S, Habib ZG, Sarki AM, et al. Nosocomial infections and resistance pattern of common bacterial isolates in an intensive care unit of a tertiary hospital in Nigeria: A 4-year review. J Crit Care 2016;34:116-20.

11. Şen Taş $S$, Kahveci K. Uzun süreli yoğun bakım ünitesi ve palyatif bakım merkezinde hastane enfeksiyonlarının sürveyansı: Üç yıllık analiz. J Contemp Med 2018;8(1):55-9.

12. MacVane SH. Antimicrobial resistance in the intensive care unit: a focus on gram-negative bacterial infections. J Intensive Care Med 2017;32:25-37.

13. Magill SS, Edwards JR, Bamberg W, Beldavs ZG, Dumyati G, Kainer MA, et al. Multistate point-prevalence survey of health care-associated infections. N Engl J Med 2014;370(13):198-208.

14. Erdem HA, Sipahi OR, Kepeli N, Dikis D, Deniz-Kucukler N, Aksoy B, et al. Point prevalence of hospitalacquired infections in Ege University Hospital. Mediterr J Infect Microbes Antimicrob 2015;4:12.

15. Tammelin A, Qvarfordt I. Point-prevalence surveillance of healthcare-associated infections in Swedish hospitals, 2008-2014. Description of the method and reliability of results. J Hosp Infect 2015;91(3):220-4

16. Bianco A, Capano MS, Mascaro V, et al. Prospective surveillance of healthcare-associated infections and patterns of antimicrobial resistance of pathogens in an Italian intensive care unit. Antimicrob Resist Infect Control 2018;3(7):48.

17. Çıragil P. Ülkemizde yoğun bakım ünitelerinde antimikrobiyal direnç sorunu. Türk Mikrobiyol Cem Derg 2016;46(3):97-104

18. Rustamov Ş. Hacettepe Üniversitesi Tıp Fakültesi Dahili Yoğun Bakım Ünitelerinde Antibiyotik Kullanımının Değerlendirilmesi. Uzmanlık Tezi 2018. Erişim:http://www.openaccess.hacettepe.edu.tr:8080/xmlui/ bitstream/handle/11655/4523/\%C5\%9Famil_rustamov_tez.pdf?sequence=1 \&isAllowed=y 